\title{
A INFLUÊNCIA DA GEOGRAFIA NO COMPORTAMENTO ELEITORAL: CONTEXTO SOCIAL DE VIZINHANÇA
}

\author{
Aleksei Zolnerkevic \\ USP - Universidade de São Paulo
}

\section{Resumo}

O tema de estudo que trata da influência da geografia nas eleições, mais especificamente da influência do contexto social ou "lugar" onde o eleitor vive, é pouco explorado pela literatura geográfica brasileira. $\mathrm{O}$ artigo apresenta as principais teorias sobre esse tema na literatura anglo-saxônica, buscando demostrar como o desenvolvimento das pesquisas nessa área no Brasil pode fazer com que a geografia alcance uma posição de maior destaque dentro dos estudos eleitorais. Por fim, apresentamos o resultado de uma pesquisa de survey na cidade de São Paulo, onde encontramos evidências da influência do contexto social de vizinhança no comportamento eleitoral.

Palavras-chave: Geografia Eleitoral, Comportamento Eleitoral, Efeitos Contextuais.
Resumen

El tema de estudio que trata de la influencia de la geografía en las elecciones, más específicamente de la influencia del contexto social o "lugar" donde vive el elector, es poco explotado por la literatura geográfica brasileña. El artículo presenta las principales teorías sobre ese tema en la literatura anglosajona, buscando demostrar cómo el desarrollo de las investigaciones en esa área en Brasil puede hacer que la geografía alcance una posición de mayor destaque dentro de los estudios electorales. Por último, presentamos el resultado de una pesquisa de survey en la ciudad de São Paulo donde encontramos evidencias de la influencia del contexto social de vecindad en el comportamiento electoral.

Palabras clave: Geografía Electoral, Comportamiento Electoral, Efectos Contextuale

\section{Introdução}

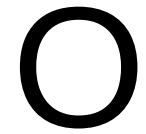

s estudos eleitorais da geografia brasileira, na sua maioria, concentram seus esforços em dois temas principais de pesquisa: "a geografia das eleições", que trata do mapeamento sistemático das eleições em busca de padrões espaciais de votação identificáveis, e "a geografia da representação política", que estuda os aspectos espaciais da representação política e da organização das eleições (CASTRO, 2005), particularmente examinando o uso do processo de territorialização do espaço como estratégia político-eleitoral dos candidatos ao legislativo com o objetivo de estabelecer a chamada "conexão eleitoral" entre candidatos e eleitores.

Segundo Taylor e Johnston (1979), existe um terceiro tema que completaria os estudos na geografia eleitoral e que tem sido pouco explorado na literatura geográfica brasileira: "a influência da geografia nas eleições". Ele busca determinar a influência da geografia, mais especificamente do contexto social (lugar, vizinhança, redes sociais), no comportamento eleitoral: como a distribuição das pessoas, a composição social dos bairros e o fluxo de informações políticas circulando 
naquele espaço influenciam o voto e qual a relação entre o comportamento eleitoral das pessoas e as diferenças entre os lugares onde elas vivem e são socializadas no que diz respeito às suas características socioeconômicas, relações de poder dentro deles, bem como em relação a outros lugares em diferentes escalas.

O presente trabalho procura apresentar as principais teorias que, juntas, fazem parte do arcabouço teórico desse tema de estudo na geografia eleitoral, desenvolvido principalmente nos países anglo-saxões, e ao mesmo tempo tenta mostrar como o desenvolvimento de pesquisas sobre esse tema no Brasil pode fazer com que a geografia alcance uma posição de maior destaque dentro dos estudos eleitorais.

Por fim, subsidiado por essa breve revisão da literatura, o artigo apresenta os resultados de uma pesquisa de survey realizada na cidade de São Paulo, durante o período da eleição para prefeito de 2016, mostrando evidências da influência do contexto social de vizinhança no comportamento eleitoral das pessoas.

\section{Uma perspectiva contextual do comportamento eleitoral}

Quando, no período eleitoral, os institutos de pesquisa apresentam suas pesquisas de intenção de voto, procuram mostrar também o perfil sociológico dos eleitores de cada candidato. Por exemplo, o candidato Lula é mais bem apoiado entre os eleitores que ganham menos de dois salários mínimos ou o candidato Bolsonaro é apoiado majoritariamente por eleitores do sexo masculino.

Essa iniciativa de apresentar o eleitorado médio dos candidatos não deixa de ser também um processo de generalização, pois obscurece o fato de que, regionalmente, há diferenças no apoio aos mesmos. O candidato Bolsonaro no seu estado natal, Rio de Janeiro, talvez tenha um apoio feminino maior do que a média nacional, o mesmo ocorrendo com o candidato Lula na região nordeste com relação aos eleitores de maior renda. Essas duas situações podem ser explicadas pelo que a literatura convencionou denominar de "efeitos contextuais", ou seja, variações no apoio eleitoral influenciadas pelo contexto social ou lugar onde os eleitores vivem.

O primeiro exemplo pode ser explicado pelo que a literatura chama de efeito contextual de "Amigos e Vizinhos" (KEY, 1949; JOHNSTON et al, 2016), que ocorre quando o candidato recebe mais votos do que o esperado na sua região natal ou de residência. Esse efeito ocorreria, por um lado, por ser mais fácil para o candidato mobilizar eleitores no lugar onde é conhecido, tem mais contatos e mais acesso às redes locais de comunicação política, e, por outro, porque em situações onde não há muitas diferenças identificáveis entre os candidatos ou um baixo interesse sobre os temas discutidos na eleição, o eleitor tende a adotar um pensamento "localista" na sua escolha votando no candidato da sua região por acreditar que ele irá melhor defender os interesses da sua comunidade. Portanto, esse efeito ocorre quando a escolha do voto do eleitor se baseia mais na sua lealdade ao lugar do que nas divisões políticas e clivagens socioeconômicas que permeiam os apoios eleitorais na escala nacional.

Segundo o modelo sociológico do comportamento eleitoral (LAZARSFELD; BERELSON; GAUDET, 1948), pessoas pertencentes aos mesmos grupos sociais tendem a decidir o seu voto para uma mesma direção. No entanto, as pessoas não decidem o seu voto de forma isolada, elas 
se informam politicamente por meio das mídias como a televisão ou o celular assim como pelas informações trazidas pelas suas redes de contato social no lugar onde vivem. Essas informações podem reforçar ou serem contraditórias em relação às predisposições sociológicas do eleitor. Mais ainda, as pessoas, quando decidem o seu voto, fazem também uma avaliação retrospectiva e prospectiva da situação econômica do lugar onde vivem, relativizando a sua condição econômica individual com a dos seus vizinhos, com a da sua região etc. (JOHNSTON; PATTIE, 2006, cap. 5).

Dessa forma, em uma sociedade politicamente polarizada, um eleitor de maior renda que teoricamente teria uma predisposição para apoiar um candidato mais à direita, estando em uma região onde durante o governo Lula a maioria pobre teve um significativo ganho na sua qualidade de vida e na sua capacidade de consumo, beneficiando a economia da região como um todo, talvez tenha uma maior probabilidade de apoiar um candidato à esquerda, influenciado pelo contato com os seus vizinhos e por causa de uma avaliação retrospectiva da condição econômica local. Esse efeito contextual é conhecido como de "Vizinhança" (TINGSTEN, 1937), e ocorre quando as interações sociais dentro do lugar onde a pessoas vivem, principalmente a conversação, trazem informações que podem reforçar as predisposições políticas dos eleitores, quando estão em consonância com a maioria, ou contradizê-las, trazendo argumentos para que os mesmos modifiquem suas posições políticas, principalmente quando há uma pressão social considerável para isso (GREGORY et al, 2009).

O geógrafo inglês Kevin Cox (1969 apud TAYLOR; JOHNSTON, 1979; JOHNSTON; PATTIE, 2006 e JOHNSTON; PATTIE, 2016) no seu estudo seminal "Progress in Geography: The voting decision in a spatial context" foi um dos primeiros a apresentar uma teoria que explicasse a causalidade por trás da relação entre comportamento político e contexto, entendido por ele como o ambiente social onde as decisões eleitorais são tomadas. No seu modelo, o contexto é visto como uma rede pela qual as informações políticas são enviadas e recebidas por "nós" (pessoas, mídias, grupos formais: igreja, organizações comunitárias etc.) que as processam e difundem através do espaço, potencialmente modificando-as. A fluidez e a difusão dessas informações dependeriam da co-localização dos "nós" e da natureza das conexões entre eles. Por exemplo, as pessoas geralmente tendem a ser mais influenciadas pelas fontes de opinião política mais próximas a elas, tanto geograficamente (distância espacial) quanto socialmente (família, amigos, colegas de trabalho etc.).

Os padrões de votação "anômalos" atribuídos a esses efeitos contextuais talvez causem a falsa impressão de que o papel da geografia eleitoral nessa linha de pesquisa seja explicar essas exceções à "regra". Os estudos do geógrafo John Agnew (1987, 1996a), quase 20 anos após Cox (1969), ao contrário, mostram que esses resultados seriam apenas a prova empírica de que o comportamento político-eleitoral é intrinsicamente geográfico e localmente estruturado.

Resgatando a ideia dos primeiros estudos da geografia eleitoral francesa de Siegfried (1913) e da americana de Turner (1926), que relacionavam a partir da comparação de mapas as características físicas, culturais e de ocupação das regiões com padrões de apoio eleitoral, mas agora buscando, assim como Cox (1969), a causalidade por trás dessa relação, Agnew (1987) considera que as escolhas político-eleitorais seriam mediadas e balizadas pelo conjunto de elementos socioeconômicos, culturais e políticos encontrados nos lugares onde as pessoas vivem e são socializadas. 
Subsidiado por teorias sociais surgidas a partir do final dos anos 1970, particularmente a teoria da estruturação de Anthony Giddens, Agnew (1987) interpreta as ações humanas como estruturadas em um contexto geográfico específico. Esse "lugar", por sua vez, seria construído a partir da intersecção entre a prática social da vida cotidiana e estruturas sociais muiltiescalares atuando localmente, que ao mesmo tempo restringem e condicionam as ações humanas ali realizadas. Essas estruturas, por outro lado, também podem ser potencialmente modificadas pela ação humana, fazendo com que os lugares estejam em um processo de constante transformação.

Para essa perspectiva, o espaço nacional deveria ser visto, então, como um mosaico de lugares onde a aceitação a propostas e movimentos políticos e sociais não ocorre de modo uniforme no espaço, uma vez que a adesão ou aceitação a elas pelas pessoas dependeria das realidades e características histórico-geográficas dos lugares onde vivem.

Em momentos de consenso, pessoas localizadas em lugares diferentes e inseridas em contextos sociais diversos, talvez irão convergir para uma mesma direção minimizando ou tornando menos importante o fato de que elas, mesmo que socialmente parecidas, localizadas em lugares diferentes, tomam suas decisões político-eleitorais baseadas em elementos igualmente diferentes. Porém, em momentos de crise, quando o interesse das pessoas está focado nos problemas específicos das suas regiões e dos lugares onde vivem, propostas eleitorais gerais talvez não alcancem o nível de aceitação desejado. Numa circunstância como essa, com os interesses seccionais se evidenciando, fica difícil compreender o comportamento eleitoral por meio de generalizações ou categorizações sociológicas sem contextualizar o eleitor no lugar onde vive. Segundo Agnew,

(...) nunca podemos explicar satisfatoriamente o que guia as escolhas e ações individuais ao menos que situemos os indivíduos no contexto social geográfico das suas vidas (...) as causas das crenças e ações políticas dos indivíduos são organizadas geosociologicamente (AGNEW, 1996b, p. 165, tradução nossa) ${ }^{1}$.

Com o aprimoramento das técnicas de geoprocessamento e a utilização de índices locais de associação espacial e pesos espaciais, as análises de abordagem ecológica que buscam mensurar o efeito de certas variáveis socioeconômicas e políticas na configuração dos padrões espaciais de votação identificados tornaram-se uma ferramenta importante para determinar a influência do contexto geográfico no comportamento eleitoral das pessoas. Além disso, recentemente, dados coletados via redes sociais virtuais como Twitter e Facebook vem sendo usados como importante fonte de informação para se determinar os interesses e as demandas geograficamente localizadas das pessoas. Campanhas políticas, como a de Donald Trump nos EUA e do referendo do Brexit no Reino Unido, supostamente teriam se beneficiado desses dados para planejar suas estratégias eleitorais, por exemplo, para decidir que discurso adotar em cada região e em que circunscrição geográfica concentrar os seus esforços de campanha².

\section{Contexto e as Redes sociais}

\footnotetext{
1 “(...) we can never satisfactorily explain what drives individual choices and action unless we situate the individuals in the social geographical contexts of their lives (...) the causes of the political beliefs and actions of individuals are organized geosociologically (AGNEW, 1996b, p.165)".

${ }_{2}$ https://motherboard.vice.com/en_us/article/mg9vvn/how-our-likes-helped-trump-win
} 
Os estudos dentro desse tema de pesquisa defendem, portanto, que além das predisposições sociológicas, o contexto social ou o lugar onde as pessoas vivem também importa no comportamento eleitoral, como um importante espaço de socialização e de aquisição de informações políticas.

De maneira análoga, o cientista político Robert Huckfeldt considera as redes sociais de comunicação política às quais os indivíduos pertencem como um fator importante para a escolha político-eleitoral e faz uma distinção importante entre contexto social e redes. Enquanto que o contexto social seria estruturalmente imposto e inescapável ao indivíduo, apresentando situações que podem trazer informações contrárias à sua opinião, as redes sociais seriam coletivamente construídas pelos seus membros (HUCKFELDT; SPRAGUE, 1987), ou seja, as pessoas escolhem interagir socialmente e pertencer a redes sociais de contanto e comunicação política homogêneas, onde seus membros têm opiniões parecidas às suas, evitando assim o desacordo. Porém, quanto maiores e mais dispersas espacialmente, essas redes formando o "espaço social" do indivíduo que não corresponde necessariamente a um contexto geográfico especifico em uma escala urbana (BAYBECK; HUCKFEDT, 2002), maior a probabilidade de haver informações dissonantes circulando dentro delas (HUCKFELDT; JOHNSON; SPRAGUE, 2004). Pessoas pertencentes a redes homogêneas tenderiam a ser mais polarizadas politicamente por causa do menor contato com opiniões divergentes, enquanto que nas redes mais heterogêneas, em relação às opiniões políticas circulando dentro delas, as pessoas seriam mais ambivalentes nas suas opiniões.

Vizinhos ou colegas de trabalho podem estar geograficamente próximos, mas não pertencer às mesmas redes sociais de informação política e, portanto, não se influenciar mutuamente. Mais ainda, quanto menos contatos e interações sociais a pessoa tem em um determinado contexto social, menor seria a influência do mesmo e menor seria o possível efeito de vizinhança daquele ambiente sobre a sua opinião política. Ou seja, em um ambiente de trabalho onde a opinião política majoritária é de direita, um trabalhador de esquerda talvez busque se isolar socialmente para evitar o desacordo com os seus colegas.

Com a diminuição dos espaços físicos de socialização como praças, clubes e áreas públicas, as redes sociais virtuais vêm se tornando cada vez mais um "lugar" ou espaço de socialização e de interação entre as pessoas, deixando ainda mais complexa a relação entre contexto social, redes sociais e comportamento político. Apesar do indivíduo receber informações políticas e estar conectado através dessas redes a "nós" localizados em outros lugares cada vez mais distantes, podemos argumentar que ele inevitavelmente interpreta as informações recebidas através do prisma e da realidade do lugar onde vive. A visibilidade dessas interpretações dentro dessas redes virtuais é justamente o que as campanhas políticas procuram encontrar e analisar para, então, traçar as suas estratégias.

A partir desse arcabouço teórico, o tema da "influência da geografia nas eleições" dentro da geografia eleitoral se apresenta como uma linha de pesquisa a ser explorada pela geografia brasileira, principalmente se considerarmos que estudos eleitorais durante o período pós-redemocratização apontam para diferenças regionais importantes no comportamento eleitoral (JACOB et al 2010, 2011), particularmente após o chamado "realinhamento eleitoral" (SINGER , 2009, 2010) e a estabilidade desse último ocorrida nas seguidas eleições presidenciais vencidas pelo PT (SOARES; TERRON, 2008, TERRON; SOARES, 2010). 


\section{Contexto social de vizinhança na Cidade de São Paulo}

Nessa parte final do artigo apresentaremos os resultados de uma pesquisa de opinião de survey realizada no ano de 2016 que procurou evidências da influência do contexto social de vizinhança na cidade de São Paulo.

Esse survey foi composto de 1395 entrevistas realizadas por telefone ${ }^{3}$ em todos os distritos da cidade. As entrevistas foram realizadas dentro de setores censitários escolhidos por sorteio e neles os entrevistados foram selecionados a partir de um sistema de cotas proporcionais ao universo de indivíduos através das seguintes variáveis: sexo, faixa de idade, escolaridade e PEA (População Economicamente Ativa).

Primeiramente foi aplicado uma técnica estatística denominada análise fatorial do modelo "S", que busca encontrar e agrupar em fatores, regiões com padrões de voto semelhantes em um determinado período de tempo (ARCHER; TAYLOR, 1981). A partir da análise dos resultados das eleições em segundo turno para presidente de 2006, 2010 e 2014 na cidade de São Paulo, na escala dos distritos administrativos, foram determinadas as regiões eleitorais de apoio duradouro ao PSDB e PT na cidade, respectivamente distritos centrais (fator I) e distritos periféricos (fator II) (figura 1).

\footnotetext{
${ }^{3}$ Como a pesquisa foi realizada por telefone (fixo), não se sabia previamente o sexo, idade, instrução, etc. do entrevistado, essas informações só eram obtidas na hora da entrevista, assim, caso o indivíduo se encaixasse na cota previamente estipulada, a entrevista era levada adiante como se fosse uma pesquisa face a face.
} 
Figura 1 - Representação cartográfica da análise fatorial do modelo "S" sobre os resultados eleitorais de PT e PSDB nas eleições presidenciais em primeiro turno de 2006 a 2014 na escala dos distritos administrativos da cidade de São Paulo, onde o fator I representa os distritos centrais e o fator II os distritos periféricos, regiões onde os eleitores historicamente apoiam PSDB e PT respectivamente.

Fator I

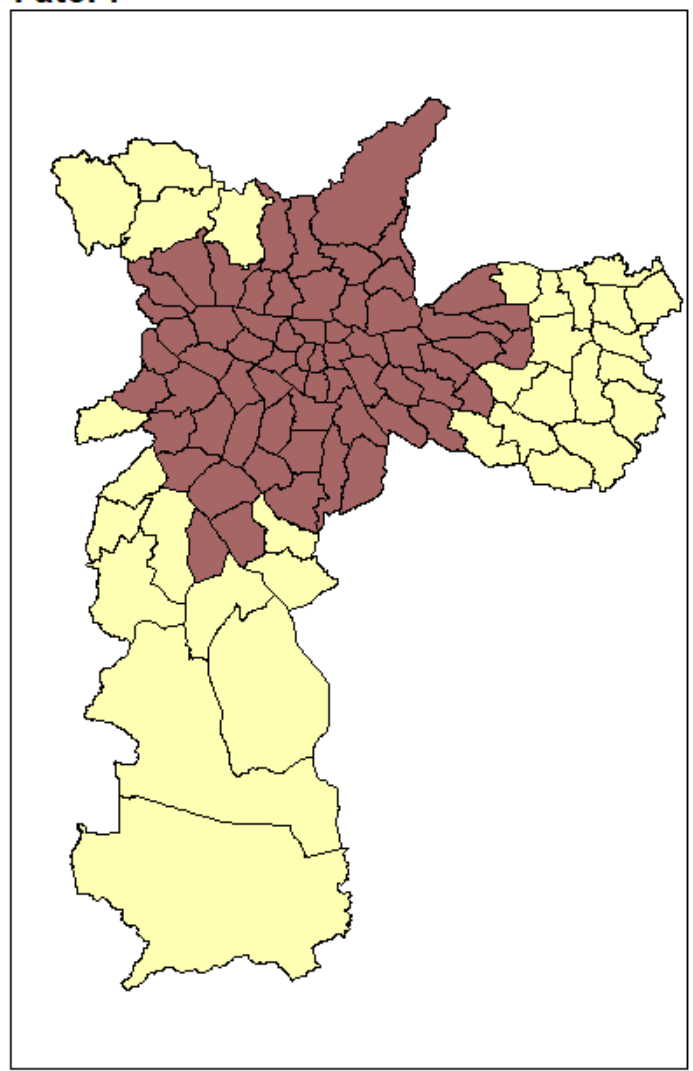

Fator II

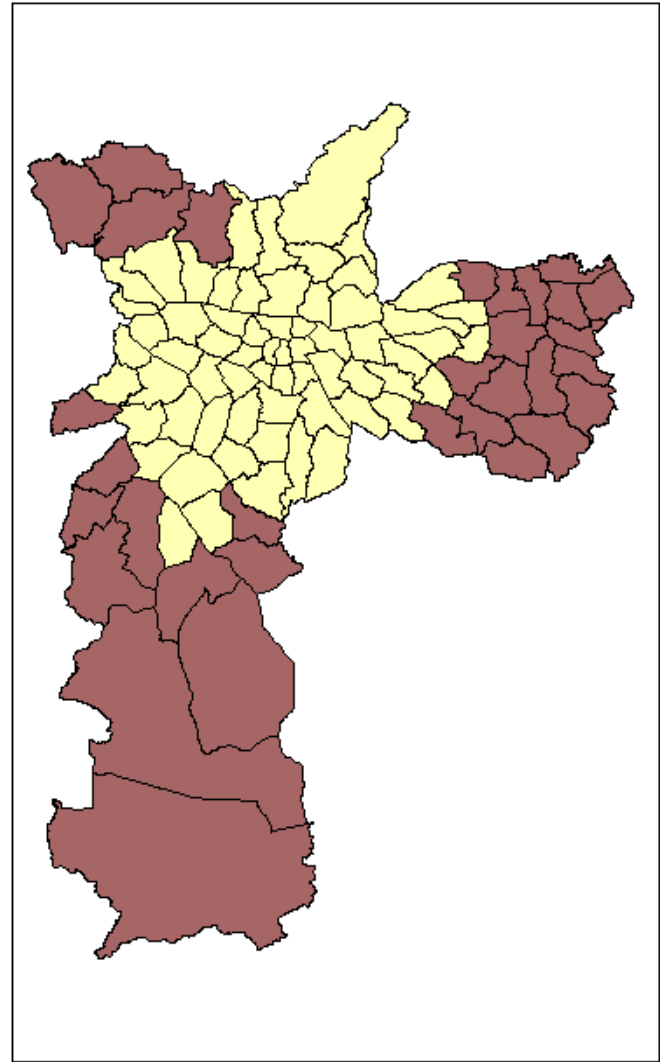

\section{Análise fatorial do modelo "S" Cargas Fatoriais}

Fonte: TSE, IBGE. Elaboração própria.

Em ambas as regiões de apoio estipuladas perguntou-se aos entrevistados, em uma escala de 0 a 10, o quanto gostam de PT e PSDB e mais duas perguntas que foram utilizadas como proxy para determinar a influência do contexto social de vizinhança no apoio eleitoral de ambos os partidos: se o entrevistado mora e trabalha no mesmo bairro e se conversa sobre política no seu local de trabalho.

A opinião média dos entrevistados sobre quanto gostam do PT e PSDB foi de 1,69 e 4,42 respectivamente, numa escala de 0 a 10. Essa nota baixa do PT pode ser atribuída ao período em que essa pesquisa foi realizada, muito próximo ao impeachment da presidente Dilma. Quando analisamos agora esses valores em cada umas das regiões de apoio, verificamos uma maior variação na opinião sobre o PT entre centro e periferia (1,34 e 2,07 respectivamente) do que sobre o PSDB 
$(4,61$ e 4,21) como pode ser estatisticamente verificado no modelo de regressão logística multivariada ordinal da tabela 1 (variável "região"): a probabilidade da pessoa gostar do PT estando na periferia é $43 \%$ maior, enquanto que morando nos distritos centrais há uma probabilidade $25 \%$ maior do indivíduo gostar do PSDB.

A regressão logística ordinal multivariada é utilizada quando se busca estudar variáveis categóricas-resposta no modelo com mais de duas categorias. A estatística qui-quadrado testa o nível de independência entre a variável dependente e os seus preditores, ou seja, se ao menos um dos coeficientes da regressão não é igual a zero; quanto maior for a significância da estatística quiquadrada (valor-p=0) maior a probabilidade de a hipótese nula ser rejeitada. Na regressão logística não há um equivalente a teste R- quadrado da regressão linear, logo utiliza-se estatísticas do grupo dos "pseudos R- quadrados" que são comparáveis ao referido teste como o Nagelkerke $\mathrm{R}^{2}$. O teste Nagelkerke $\mathrm{R}^{2}$ fornece resultados entre 0 e 1 mostrando em porcentagem o quanto o modelo é capaz de explicar as variações observadas na variável dependente, podendo ser usado para comparar modelos de regressão concorrentes.

As variáveis composicionais no modelo (idade, instrução, renda, PEA) exerce um papel de "controle" no efeito das variáveis contextuais sobre a variável dependente (gostar do PT/PSDB). Esse "controle" pode mostrar que apesar das variáveis contextuais estarem relacionadas com certas características sócio demográficas, elas por si só exercem influência sobre a variável dependente.

Tabela 1. Modelo de regressão multivariada ordinal para a variação regional no apoio aos partidos PT e PSDB na cidade de São Paulo controlado por algumas variáveis composicionais socioeconômicas.

\begin{tabular}{|c|c|c|c|}
\hline \multicolumn{2}{|l|}{ Variáveis } & \multirow{3}{*}{$\begin{array}{l}\text { O quanto gosta do } \\
\text { PT } \\
-, 318^{*} \\
(, 144)\end{array}$} & \multirow{2}{*}{$\begin{array}{l}\text { PSDBB } \\
, 218\end{array}$} \\
\hline \multirow{10}{*}{$\begin{array}{l}\text { Composicionais } \\
\text { (de controle) }\end{array}$} & Sexo & & \\
\hline & & & $(, 130)$ \\
\hline & Idade &,$- 339 * * *$ &, $235 * * *$ \\
\hline & & $(, 077)$ & $(, 069)$ \\
\hline & Instrução &,- 012 &,$- 134 *$ \\
\hline & & $(, 074)$ & $(, 065)$ \\
\hline & Renda &,- 251 & ,272* \\
\hline & & $(, 143)$ & $(, 131)$ \\
\hline & PEA &,- 182 & ,236 \\
\hline & & $(, 145)$ & $(, 130)$ \\
\hline \multirow[t]{5}{*}{ Contextuais } & Região &,$- 438 * * *$ & ,250* \\
\hline & & $(, 136)$ & $(, 122)$ \\
\hline & Qui- quadrado & $47,979 * * *$ & 43,547 ****: \\
\hline & $\mathbf{R}^{2}$ Nagelkerke & 054 &, 050 \\
\hline & $\mathbf{N}$ & 919 & 870 \\
\hline
\end{tabular}

Fonte: APPC, elaboração própria.

Notas: Coeficientes estatisticamente significantes em negrito. Erro padrão entre parênteses. Nível de significância(Valor-p): ${ }^{* \star *}<, 001, * \star<, 01, *<, 05$. 
Variáveis: Sexo: (1) = Masculino, (2) = Feminino; Idade: (1) = 16 a 24, (2) = 25 a 44, (3) = 45 a 59, (4)>=59 anos; Instrução: (1) = ensino fundamental, (2) = Médio, (3) = Superior; Renda: (1) = até 2SM, (2) > de 2 SM; PEA: (1) = sim, (2) = não; Região: (1) = Periferia, (2) = Centro.

Verificamos que quando o entrevistado na região de apoio ao PT diz que trabalha no seu bairro de residência, a nota média ao partido sobe para 2,92 pontos, enquanto que entre os que trabalham fora a nota é de 1,91 pontos. Mais ainda, entre aqueles que trabalham no bairro e costumam conversar sobre política, a nota média sobe para 3,24 pontos e a probabilidade de gostar do partido é 77\% maior (tabela 2, coluna: periferia, modelo B). Em outras palavras, o indivíduo que mora na região de apoio eleitoral do PT, distritos periféricos, apresenta uma maior tendência de gostar do partido e essa tendência varia de acordo com a configuração da sua rede de interação social. O indivíduo que mora e trabalha na periferia e conversa sobre política tende a gostar mais do partido do que, por exemplo, aquele que não conversa sobre política e que, portanto, está menos conectado com a rede de comunicação política local.

Tabela 2. Modelo de regressão multivariada ordinal para a variação do apoio ao PT nos distritos periféricos da cidade de São Paulo de acordo com o padrão de interação social dos residentes. Modelo A considera separadamente as variáveis: trabalha no mesmo bairro que mora e conversa sobre política, já o modelo B junta essas duas perguntas numa variável única.

\begin{tabular}{|c|c|c|c|c|c|}
\hline \multicolumn{6}{|c|}{ O quanto gosta do PT } \\
\hline \multirow{2}{*}{\multicolumn{2}{|c|}{ Variáveis }} & $\begin{array}{l}\text { Região } \\
\text { Periferia }\end{array}$ & & Centro & \\
\hline & & $\mathbf{A}$ & B & $\mathbf{A}$ & B \\
\hline \multirow{10}{*}{$\begin{array}{l}\text { Composicionais } \\
\text { (de controle) }\end{array}$} & Sexo &, 051 & 089 &,- 540 &,$- 568 *$ \\
\hline & & $(, 286)$ & $(, 283)$ & $(, 295)$ & $(, 294)$ \\
\hline & Idade &,$- 474 * *$ &,$- 400 *$ &,- 323 &,$- 332 *$ \\
\hline & & $(, 178)$ & $(, 171)$ & $(, 170)$ & $(, 168)$ \\
\hline & Instrução &, 116 &, 157 &, 046 &, 076 \\
\hline & & $(, 177)$ & $(, 173)$ & $(, 152)$ & $(, 151)$ \\
\hline & Renda &,$- 576^{*}$ &,- 538 &,- 372 &,- 292 \\
\hline & & $(, 298)$ & $(, 292)$ & $(, 330)$ & $(, 323)$ \\
\hline & PEA &,- 081 &,- 216 &,- 071 &,- 042 \\
\hline & & $(, 398)$ & $(, 388)$ & $(, 486)$ & $(, 480)$ \\
\hline \multirow{9}{*}{ Contextuais } & Trabalha e mora &,$- 582 *$ & - & 601 & - \\
\hline & & $(, 303)$ & & $(, 319)$ & \\
\hline & Conversa & ,207* & - &, 056 & - \\
\hline & & $(, 102)$ & & $(, 101)$ & \\
\hline & Trabalha e mora+ conversa & - &, $773 *$ & - &,- 597 \\
\hline & & & $(, 357)$ & & $(, 395)$ \\
\hline & Qui- quadrado & $18,441 * *$ & $15,207 *$ & 12,064 & 10,434 \\
\hline & $\mathbf{R}^{2}$ Nagelkerke & ,089 &, 074 &, 056 &, 048 \\
\hline & $\mathbf{N}$ & 205 & 205 & 224 & 224 \\
\hline
\end{tabular}

Fonte: APPC, elaboração própria.

Notas: Coeficientes estatisticamente significantes em negrito. Erro padrão entre parênteses. Nível de significância (Valor-p) ${ }^{* \star *}<, 001,{ }^{* *}<, 01,{ }^{*}<, 05$. 
Variáveis: Sexo: (1) = Masculino, (2) = Feminino; Idade: (1) = 16 a 24, (2) = 25 a 44, (3) = 45 a 59, (4)>=59 anos; Instrução: (1) = ensino fundamental, (2) = Médio, (3) = Superior; Renda: (1) = até 2SM, (2) > de 2 SM; PEA: (1) = sim, (2) = não; Trabalha no mesmo bairro que mora: (1) = sim, (2) = não; Conversa sobre política: $(1)=$ Nunca, $(2)=$ Raramente, (3) = Às vezes, (4) = Quase sempre, (5) = Sempre; Trabalha e mora + conversa: (0) Não trabalha no mesmo bairro que mora e não conversa sobre política (1) Trabalha no mesmo bairro que mora e conversa sobre política [Ás vezes, Quase sempre, Sempre].

Já em relação ao PSDB, aquele indivíduo que mora na periferia, mas não trabalha no mesmo bairro em que mora, tem uma maior tendência a gostar do PSDB (57\% na Tabela 3), supondo-se que esse indivíduo provavelmente trabalha na região central e, portanto, está mais exposto a um contexto social de vizinhança mais favorável ao partido. Esse argumento é reforçado se considerarmos que o indivíduo que mora nos distritos centrais, região de apoio ao PSDB, tende a gostar mais do partido se ele pertence a uma rede de comunicação local: entre os que dizem conversar sempre sobre política no local de trabalho, a nota para o partido é 4,65 pontos, enquanto que entre os que afirmam nunca conversar sobre política é de 3,66 pontos.

Tabela 3. Modelo de regressão multivariada ordinal para a variação do apoio ao PSDB nos distritos periféricos e centrais da cidade de São Paulo de acordo com o padrão de interação social dos residentes.

\begin{tabular}{|c|c|c|c|}
\hline & \multicolumn{3}{|c|}{ O quanto gosta do PSDB } \\
\hline \multirow[b]{2}{*}{ Variáveis } & & \multicolumn{2}{|l|}{ Região } \\
\hline & & Periferia & Centro \\
\hline \multirow{10}{*}{$\begin{array}{l}\text { Composicionais } \\
\text { (de controle) }\end{array}$} & Sexo & ,293 & ,307 \\
\hline & & $(, 275)$ & $(, 263)$ \\
\hline & Idade &, $427 * *$ & ,343* \\
\hline & & $(, 166)$ & $(, 151)$ \\
\hline & Instrução &,- 256 &,- 129 \\
\hline & & $(, 164)$ & $(, 137)$ \\
\hline & Renda & 062 &, 074 \\
\hline & & $(, 281)$ & $(, 295)$ \\
\hline & PEA &,- 137 &,- 223 \\
\hline & & $(, 362)$ & $(, 414)$ \\
\hline \multirow[t]{7}{*}{ Contextuais } & Trabalha e mora &, $579 *$ &,- 183 \\
\hline & & $(, 289)$ & $(, 274)$ \\
\hline & Conversa &,- 005 &, $238 * *$ \\
\hline & & $(, 096)$ & $(, 090)$ \\
\hline & Qui- quadrado & $14,449 *$ & $13,673 *$ \\
\hline & $\mathbf{R}^{2}$ Nagelkerke &, 073 &, 062 \\
\hline & $\mathbf{N}$ & 194 & 216 \\
\hline
\end{tabular}

Fonte: APPC, elaboração própria.

Notas: Coeficientes estatisticamente significantes em negrito. Erro padrão entre parênteses. Nível de significância(Valor-p): ${ }^{* *}<, 001,{ }^{* *}<, 01,{ }^{*}<, 05$.

Variáveis: Sexo: (1) = Masculino, (2) = Feminino; Idade: (1) = 16 a 24, (2) = 25 a 44, (3) = 45 a 59, (4)>=59 anos; Instrução: (1) = ensino fundamental, (2) = Médio, (3) = Superior; Renda: (1) = até 2SM, (2) > de 2 SM; PEA: (1) = sim, (2) = não; Trabalha no mesmo bairro que mora: $(1)=\operatorname{sim},(2)=$ não; Conversa sobre política: $(1)=$ Nunca, $(2)=$ Raramente, (3) = Às vezes, (4) = Quase sempre, (5) = Sempre. 


\section{Conclusão}

É importante demonstrar através de mapas e análises estatísticas multivariadas a correspondência entre as características socioeconômicas das circunscrições geográficas (bairros, distritos, municípios etc.) com certos padrões eleitorais de votação, porém, mais do que isso, é importante também buscar a causalidade por trás dessa relação, ou seja, o "como" é tão importante quanto o "porque". Os estudos dentro do tema da geografia eleitoral que investigam a influência da geografia nas eleições buscam justamente estudar essa questão: como a localização do eleitor, as características do lugar onde a pessoa vive e as informações políticas que circulam dentro de um contexto social especifico influenciam a escolha eleitoral.

A nossa pesquisa de survey em São Paulo mostra como a variação dos padrões de interação social dos indivíduos modula a influência do contexto de vizinhança na sua escolha eleitoral. Os resultados sugerem que o indivíduo que permanece mais no seu contexto de vizinhança e pertence a uma rede de comunicação política local tem uma maior tendência a apoiar o partido historicamente mais forte naquela região. Esse resultado pode ser visto, então, como uma evidência da influência do contexto de vizinhança no comportamento eleitoral na cidade de São Paulo.

Enquanto alguns resultados eleitorais evidenciam a dinâmica contextual ou geográfica do comportamento eleitoral, muitos outros a obscurecem. Nesse sentido, a geografia brasileira teria um espaço a preencher nos estudos eleitorais, particularmente sobre comportamento eleitoral, que é o da defesa de uma perspectiva contextual sobre as eleições.

Com o crescimento da oferta de dados que podem ser usados para se determinar os interesses e demandas geograficamente localizados das pessoas, essas informações já estariam sendo usadas pelas campanhas políticas para planejar suas estratégias eleitorais. O papel da academia, nesse aspecto, seria o de desenvolver estudos científicos, mostrando como essas informações podem ser utilizadas para compreender melhor a dinâmica geo-sociológica do voto e o comportamento político como um todo. 
Referências

AGNEW, John. Place and Politics: The Geographical Mediation of State and Society. Boston: Allen and Unwin, 1987.

AGNEW, John. Mapping Politics: How Context Counts in Electoral Geography. Political Geography, v.15, n.2, p. 129-46, 1996a.

AGNEW, John. Maps and Models in Political Studies: A Reply to Comments. Political Geography, v. 15, n.2, p.165-167, 1996b.

ARCHER, J. Clark; TAYLOR, Peter J. Section and Party: A Political Geography of American Presidential Elections, form Andrew Jackson to Ronald Reagan. Chichester: Wiley, 1981.

BAYBECK, Brady; HUCKFELDT, Robert. Urban contexts, spatially dispersed networks, and the diffusion of political information. Political Geography, v.21, n.2, p.195-220, 2002.

CASTRO, Iná Elias de. Geografia e Política: Território, escala de ação e instituições. Rio de Janeiro: Bertrand Brasil, 2005.

GREGORY, Derek et. al. (Org.) The Dictionary of Human Geography. 5th ed. Oxford: Wiley-Blackwell, 2009.

HUCKFELDT, Robert; SPRAGUE, John. Networks in context: the social flow of political information. The American Political Science Review, v. 81, n.4, p.1197-1216, 1987.

HUCKFELDT, Robert; JOHNSON, Paul E.; SPRAGUE, John. The survival of diverse opinions within communication networks. New York, NY, USA: Cambridge University Press, 2004.

JOHNSTON, Ron J.; PATTIE, Charles. Putting Voters in Their Place: Geography and Elections in Great Britain. New York: Oxford University Press, 2006.

JOHNSTON, Ron J.; PATTIE, Charles. "Kevin Cox and Electoral Geography". In: JONAS, Andrew E. G.; WOOD, Andrew (ed.) In Territory, the State and Urban Politics. New York: Routledge, 2016.

JOHNSTON, Ron J. et al. Friends and neighbours voting revisited: the geography of support for candidates to lead the UK's Labour party. Political Geography, v. 55, p.1- 9, 2016.

KEY, Valdimer O. Southern Politics. New York: Random House, 1949.

LAZARSFELD, Paul F.; BERELSON Bernard; GAUDET, Hazel. The People's Choice: How the Voter Makes Up His Mind in a Presidential Campaign. New York: Columbia University Press, 1948.

SIEGFRIED, André. Tableau politique de la France de l'Ouest sous la Troisième République. Paris: Colin, 1913.

TAYLOR, Peter J.; JOHNSTON, Ron J. The Geography of Elections. Harmondsworth: Penguin, 1979.

TINGSTEN, Herbert L. G. Political Behavior. Totowa, NJ: Bedminster, 1937.

TURNER, Frederick. J. The Significance of Sections in American History. New York: Holt, 1932. 